\title{
ЗЕЛЕНЫЕ ОБЛИГАЦИИ ОАО «РЖД», КАК ИНСТРУМЕНТ РАЗВИТИЯ ИНФРАСТРУКТУРЫ И НОВАЯ СИСТЕМА УПРАВЛЕНИЯ ТРАНСПОРТОМ
}

\section{GREEN RUSSIAN RAILWAYS BONDS, AS A TOOL FOR INFRASTRUCTURE DEVELOPMENT AND A NEW TRANSPORT MANAGEMENT SYSTEM}

O. Selina

Summary. Russian Railways (Russian Railways) is a state-owned company that owns and operates the Russian railway network and infrastructure. The company issued the first international green bond in the Russian Federation. This is what became the main topic of the article. It will use several questions: like all those who became an investor in this project. In addition, the article analyzes the amount of $\mathrm{CO} 2$ emissions from rail, road and air modes of transport.

Keywords: Russian railways, green bonds, investments, electrified trains. $\mathbf{0}$ АО «РЖД» выпустило первую «зеленую» облигацию компании и первую международную «зеленую» облигацию, выпущенную российской компанией. 8-летняя «Green Bond» привлекла 500 миллионов евро и была, в итоге, оценена в 2,2\%. Выпуск был подготовлен в соответствии с принципами «зеленых» облигаций Международной ассоциации рынков капитала и сертифицирован в рамках Инициативы по климатическим облигациям. Подтверждение было предоставлено «Sustainalytics», ведущей независимой исследовательской и рейтинговой компанией ESG и корпоративного управления [3].

Большинством, кто вложил свои средства в «Зеленые облигации», являются иностранные инвесторы (более $75 \%)$. Российские инвесторы владеют около $25 \%$ «зеленых» облигаций. Что касается географической разбивки книги заказов «зеленых» облигаций, то более $30 \%$ - Германия, Австрия, $15 \%$ - Великобритания, $11 \%$ - Швейцария, 14\% - инвесторы стран континентальной Европы, 4\% - страны Азии, 1\% - США (рис. 1) [4].

Не стоит забывать, что сама компания в 2018 г. инвестировала в экологическую безопасность 8,5 млрд. руб. Это позволило компании сократить вредные выбросы в атмосферу на 4,3\%, сбросы загрязненных сточных вод на $11 \%$ и устранить 12 участков накопленного эколо-
Селина Ольга Викторовна

К.э.н., дочент, ФГБОУ ВО Уральский государственный университет путей сообщения (гор. Екатеринбург) ovselina@usurt.ru

Аннотация. Российские железные дороги («РЖД») — государственная компания, которая владеет и управляет железнодорожной сетью и инфраструктурой России. Не так давно компания выпустила первую международную зеленую облигацию в Российской Федерации. Именно это стало основной темой статьи. В ней будут рассматриваться несколько вопросов: как повлияют «Зеленые облигации» на развитие РЖД и экологическую обстановку в России, и кто же стал инвесторами в данном проекте. Кроме того, в статье анализируется количество выбросов СО2 от железнодорожных, автомобильных и воздушных видов транспорта.

Ключевые слова: Российские железные дороги, зеленые облигации, инвестиции, электрифицированные поезда.

гического ущерба (например, нефтепродукты, склады и ремонтные мастерские, отработанное мазут, дизельное топливо и другие химические соединения). Каковы будут результаты от «Зеленых облигаций», нам предстоит только догадываться. Однако ОАО «РЖД» уже предоставили примерный план вложения.

Привлеченный капитал будет использован для покупки электропоездов, поскольку РЖД продолжает модернизировать свой подвижной состав, постепенно отказываясь от дизельных и старых электропоездов. Также средства облигации будут направлены на финансирование и рефинансирование покупки пассажирских электропоездов "Ласточка», увеличив число действующих поездов на 183 к 2021 г. Поезда будут выполнять пассажирские транзитные функции на пригородных и междугородних маршрутах. Кроме того, компания объявила о планах приобрести 1000 новых электровозов в течение следующих трех лет по цене около 2 млрд. евро [2].

Программа 2025 г. также предусматривает приобретение нового подвижного состава и модернизацию существующего парка, включая тяговые агрегаты, а также внедрение новой технологии для ускорения развития цифровых технологий. Планируется модернизировать и расширить магистральную инфраструктуру, в том 


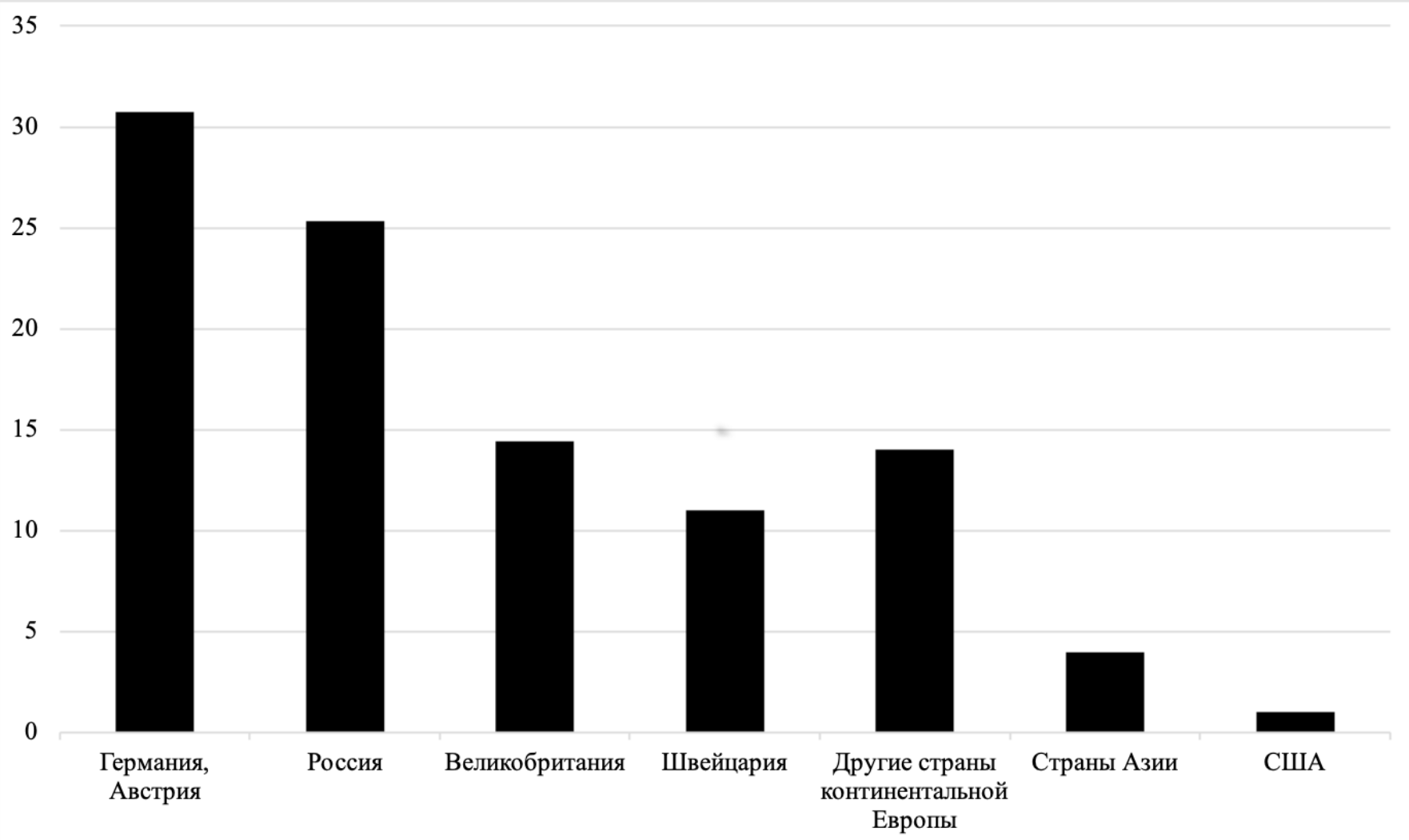

Рис. 1. Инвесторы «зеленых» облигаций

Источники: Авторский расчет на основе данных, заявленных Ириной Лолуа, исполнительным директором JP Morgan в России.

числе железнодорожную сеть в Азово-Черноморском бассейне, а также развивать Байкало-Амурскую и Транссибирскую железнодорожные линии. Для Байкало-Амурской и Транссибирской модернизации до 2025 года необходимо инвестировать около 3 млрд. долларов США. Проекты должны способствовать увеличению контейнерных перевозок в четыре раза, в том числе сокращению времени железнодорожных контейнерных перевозок, в частности от Дальнего Востока до западной границы России до семи дней.

Как мы знаем, железнодорожный транспорт является одним из самых экологически чистых видов транспорта. Энергоэффективность железнодорожного транспорта лучше, чем автомобильного, в 2-3 раза, как в грузовых, так и в пассажирских перевозках. Более половины (43,8 тыс. км) из 85,6 тыс. км эксплуатационной длины российских железных дорог электрифицировано. Кроме того, более $86 \%$ грузов и пассажиров перевозятся по электрифицированным железнодорожным системам. Электрификация наиболее загруженных линий страны и вывод из эксплуатации тепловозов являются одним из стратегических приоритетов ОАО «РЖД» [1].
По данным Международного энергетического агентства и Международного союза железных дорог, ОАО «РЖД» - одна из самых энергоэффективных железнодорожных компаний во всем мире. Россия занимает первое место по энергоэффективности грузовых железнодорожных перевозок по сравнению с другими европейскими железнодорожными системами, железными дорогами Китая, Японии, Индии и США, и занимает четвертое место по энергоэффективности пассажирских железнодорожных перевозок после Индии, Китая и Японии.

Кроме того, в связи с увеличением количества рейсов пассажиров из городских центров в близлежащие регионы, холдинг РЖД строит свою электрифицированную сеть и подвижной состав, чтобы предлагать перевозки по наилучшему сочетанию скорости и цены и с минимально возможным воздействием углерода. Маршруты с интенсивным движением, по прогнозам, возрастут, и действия ОАО «РЖД» должны помочь отвлечь путешественников от автомобилей и автобусов на электрифицированные поезда [1].

Железнодорожные перевозки уже предлагают значительные преимущества перед автомобильными и воз- 


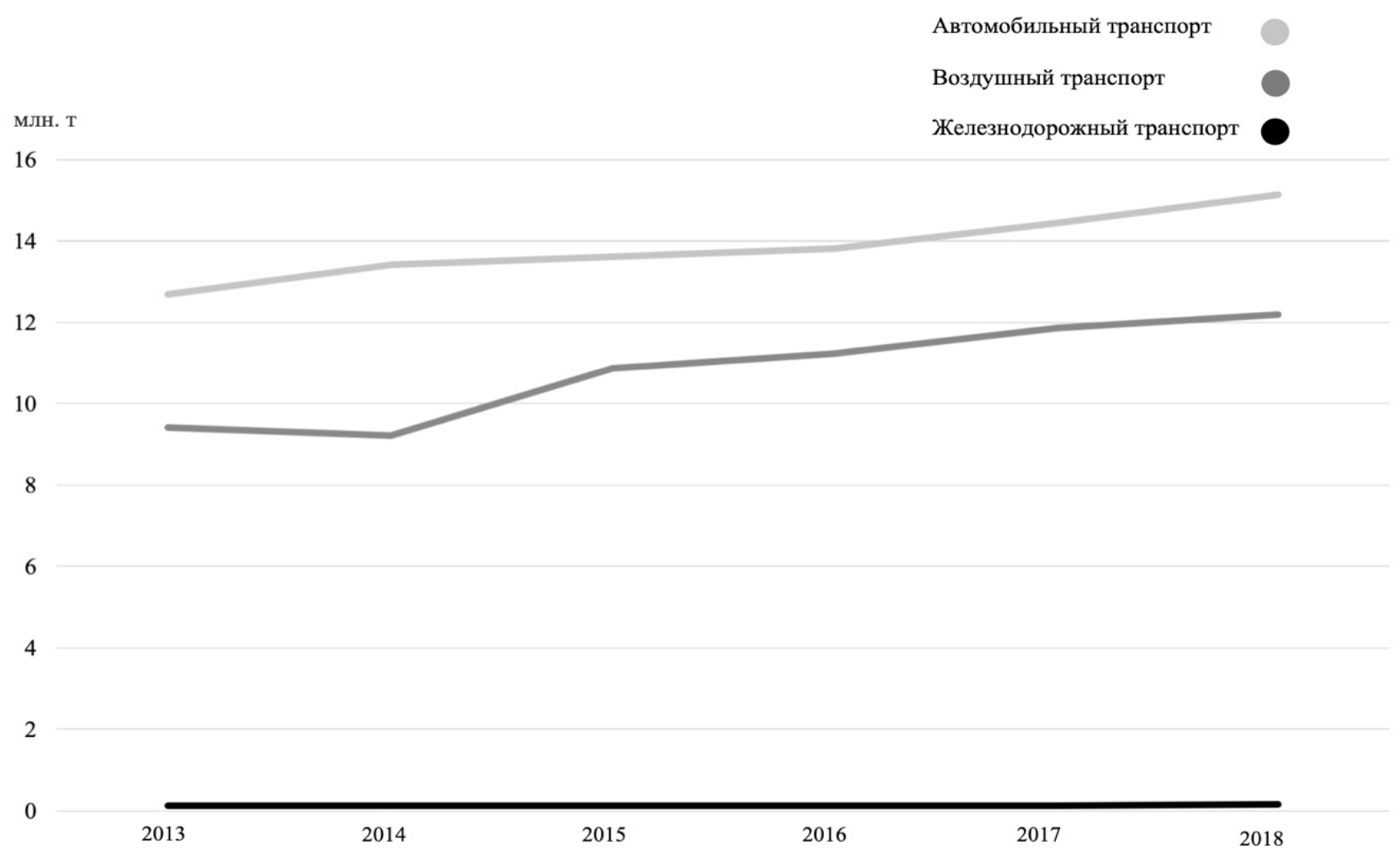

Рис. 2. Эмиссия $\mathrm{CO}_{2}$ разными видами транспорта

Источники: Авторский расчет на основе данных аналитического центра при правительстве Российской Федерации.

душными перевозками с точки зрения выбросов СО2 и потребления ресурсов. Новое поколение поездов «Ласточка» снова улучшит эти показатели, достигнув выбросов СO2, как правило, в 3,5 раза ниже, чем автомобильного транспорта, и почти в 10 раз ниже, чем воздушного транспорта.

Однако, в то время как у железных дорог, естественно, меньше выбросов, чем у других видов транспорта, ОАО «РЖД» поставила перед собой амбициозные цели по постоянному улучшению своих экологических показателей, стремясь к 2030 г. вдвое сократить общее воздействие на окружающую среду.

Постоянные инвестиции в базу активов позволяют Российским железным дорогам добиваться этих сокращений и дают дополнительную выгоду, привлекая пассажиров в поезда и избегая более экологически вредных видов транспорта [5].

Помимо электрификации сети и локомотивов, ОАО «РЖД» проводит все более и более развитую экологическую политику, в том числе:
1. 56 лабораторий по всей стране измеряют и сообщают о выбросах в разных местах, а также регулярно проверяют поезда;

2. годовые цели сокращения выбросов, использования пластмасс и воды;

3. «Зеленый день» для всей компании каждый месяц, поощряющий осведомленность сотрудников и пассажиров;

4. текущая программа посадки деревьев;

5. переработка старых железнодорожных шпал в биомассу и коммунальные системы отопления.

Одной из ключевых стратегических целей ОАО «РЖД» к 2030 г. является приоритетное использование экологически чистых технологий и двукратное снижение нагрузки на окружающую среду, признавая, что железная дорога по-прежнему является одним из видов транспорта с самым низким уровнем вредного воздействия на окружающую среду [6].

Таким образом, можно утверждать, что инвестиционная привлекательность компании ОАО РЖД на современном этапе представляет собой высокий уровень. 


\section{ЛИТЕРАТУРА}

1. Б Бурмистрова С., Казарновский П. «Зеленым» кредитам дают зеленый свет // Официальный сайт информационного агентства «РБК» [Электронный ресурс].

2. Жундриков А., Якунина Е. Инвестиции в инфраструктуру // Российская независимая инвестиционная компания Infraone No9, 23.04-21.05.2019. (Дата 06ращения: 28.03 .2020 г.).

3. Третьяк А., Штанов В., Астапенко А. Российская компания впервые выпустит зеленые евробонды // Электронное периодическое издание «Ведомости» [Электронный ресурc]. URL: https://www.vedomosti.ru/ business/articles/2019/05/08. / (Дата обращения: 02.04 .2020 г.).

4. Интервью С Ириной Лолуа, исполнительным директором JP Morgan в России // 000 «РЖД ТВ» [Электронный ресурc]. URL: https://www.rbc.ru/newspaper/2 020/02/25/5e4f9b4c9a7947c073db340f (Дата обращения: 26.03 .2020 г.).

5. Селина 0. В. Особенности реализации целевой программы в ОАО РЖД на современном этапе развития холдинга // Фундаментальные исследования.2015. — № 11-6. — С. 1249-1252.

6. Юрин К. С., Обухова О. В. Модернизация железнодорожного транспорта, как фактор повышения качества транспортного обслуживания //Управление экономическими системами: электронный научный журнал.— 2012. — № 12 (48).— С. 44.

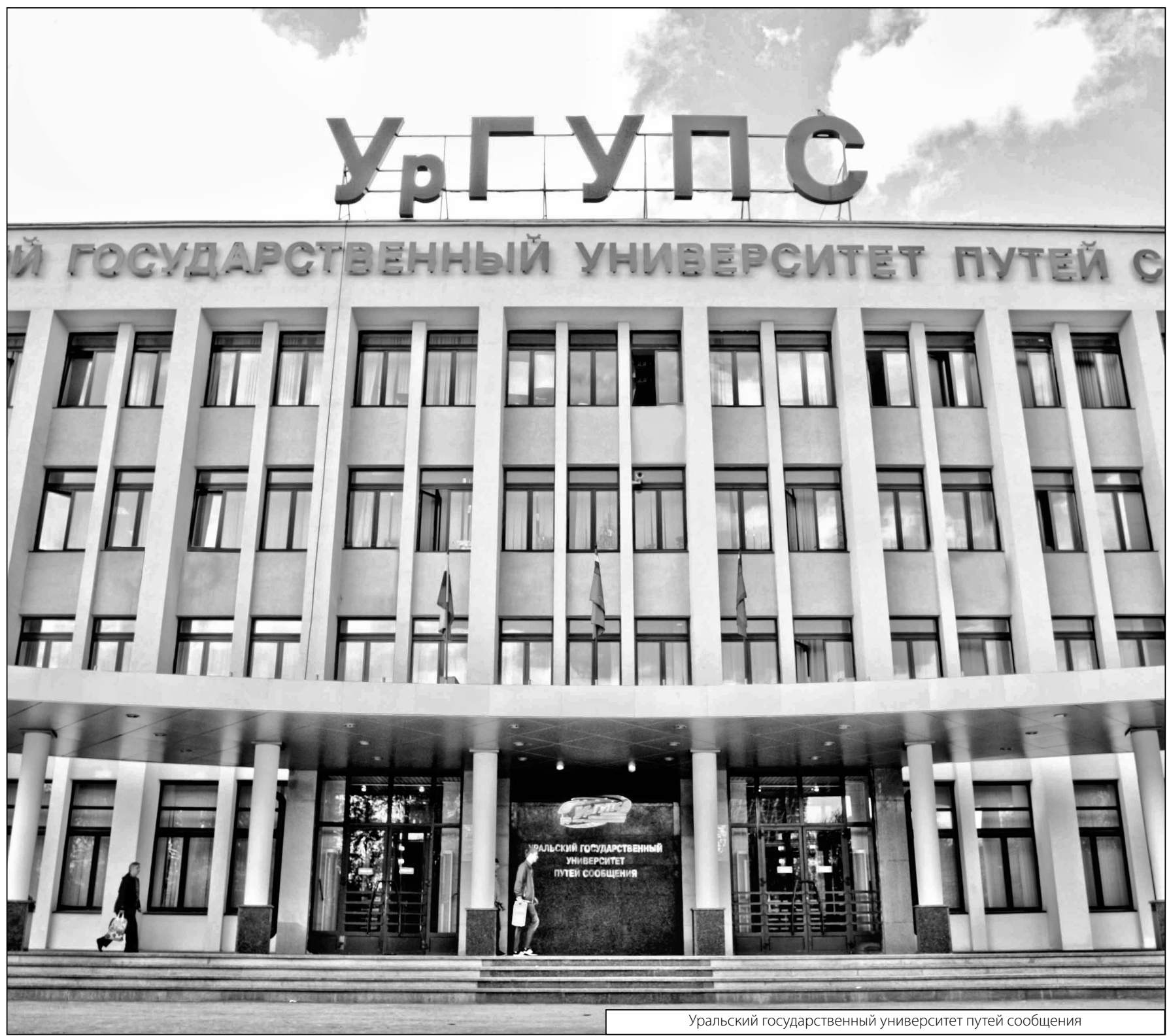

